\title{
Hepatic lipase expression in macrophages contributes to atherosclerosis in apoE-deficient and LCAT-transgenic mice
}

\author{
Zengxuan Nong, ${ }^{1}$ Herminia González-Navarro, ${ }^{1}$ Marcelo Amar, ${ }^{1}$ Lita Freeman, ${ }^{1}$ \\ Catherine Knapper, ${ }^{1}$ Edward B. Neufeld, ${ }^{1}$ Beverly J. Paigen, ${ }^{2}$ Robert F. Hoyt, ${ }^{3}$ \\ Jamila Fruchart-Najib, ${ }^{4}$ and Silvia Santamarina-Fojo ${ }^{1}$ \\ ${ }^{1}$ Molecular Disease Branch, National Heart, Lung, and Blood Institute, NIH, Bethesda, Maryland, USA \\ ${ }^{2}$ The Jackson Laboratory, Bar Harbor, Maine, USA \\ ${ }^{3}$ Laboratory of Animal Medicine and Surgery, Heart, Lung, and Blood Institute, NIH, Bethesda, Maryland, USA \\ ${ }^{4}$ Department d'Atherosclerose, Institut Pasteur, Lille, France
}

\begin{abstract}
Hepatic lipase (HL) has a well-established role in lipoprotein metabolism. However, its role in atherosclerosis is poorly understood. Here we demonstrate that HL deficiency raises the proatherogenic apoB-containing lipoprotein levels in plasma but reduces atherosclerosis in lecithin cholesterol acyltransferase (LCAT) transgenic (Tg) mice, similar to results previously observed with HL-deficient apoE-KO mice. These findings suggest that HL has functions that modify atherogenic risk that are separate from its role in lipoprotein metabolism. We used bone marrow transplantation (BMT) to generate apoE-KO and apoE-KO $\times$ HL-KO mice, as well as LCAT-Tg and LCAT-Tg $\times$ HL-KO mice, chimeric for macrophage HL gene expression. Using in situ RNA hybridization, we demonstrated localized production of HL by donor macrophages in the artery wall. We found that expression of HL by macrophages enhances early aortic lesion formation in both apoE-KO and LCAT-Tg mice, without changing the plasma lipid profile, lipoprotein lipid composition, or HL and lipoprotein lipase activities. HL does, however, enhance oxidized LDL uptake by peritoneal macrophages. These combined data demonstrate that macrophage-derived HL significantly contributes to early aortic lesion formation in two independent mouse models and identify a novel mechanism, separable from the role of HL in plasma lipoprotein metabolism, by which HL modulates atherogenic risk in vivo.
\end{abstract}

J. Clin. Invest. 112:367-378 (2003). doi:10.1172/JCI200316484.

\section{Introduction}

Hepatic lipase (HL) is a 64-kDa glycoprotein that plays a major role in lipoprotein metabolism. HL is synthesized primarily by hepatocytes but is also present in steroidogenic tissues (1-3). The enzyme hydrolyzes triglycerides (TGs) and phospholipids (PLs) in chylomicron remnants (CRs), IDL, and HDL, thereby altering lipoprotein size and density $(1,4,5)$. HL is an important determinant of plasma HDL concentra-

Received for publication July 23, 2002, and accepted in revised form May 20, 2003.

Address correspondence to: Silvia Santamarina-Fojo, Molecular Disease Branch, National Heart, Lung, and Blood Institute, NIH, Building 10, Room 7N115, Bethesda, Maryland 20892, USA. Phone: (301) 496-5095; Fax: (301) 402-0190; E-mail: silvia@mdb.nhlbi.nih.gov.

Conflict of interest: The authors have declared that no conflict of interest exists.

Nonstandard abbreviations used: hepatic lipase (HL); lecithin cholesterol acyltransferase (LCAT); transgenic (Tg); bone marrow transplantation (BMT); triglyceride (TG); phospholipid (PL); chylomicron remnant (CR); coronary artery disease (CAD); lipoprotein lipase (LPL); fetal liver cell (FLC); lipoproteindeficient serum (LPDS); fast protein liquid chromatography (FPLC); cholesteryl ether (CEt); oxidized LDL (OxLDL); trichloroacetic acid (TCA). tions (6-10) and LDL subclass distribution (6, 9-11), which predict atherogenic risk. In addition to its role as a lipolytic enzyme, HL has a separate function in lipoprotein metabolism as a ligand that facilitates the cellular uptake of lipoproteins or lipoprotein lipids by cell surface receptors and/or proteoglycans $(5,12,13)$. Expression of wild-type and catalytically inactive HL in different animal models has demonstrated HLmediated metabolism of CRs and HDL independent of lipolysis (14-16). In addition, the presence or absence of HL protein in patients deficient in HL activity leads to significant differences in the cholesterol content of apoB-containing lipoproteins (17). These combined data have established the physiologic relevance of the ligand-binding function of $\mathrm{HL}$ in vivo.

Despite recent advances in our understanding of $\mathrm{HL}$ function in lipoprotein metabolism and cellular lipid uptake, the role this enzyme plays in atherosclerosis is still poorly understood. Reduced postheparin plasma HL activity has been associated with increased coronary artery disease (CAD) in patients with type 1 diabetes, cholesteryl ester transfer protein deficiency, familial hypercholesterolemia, HL deficiency, and HL gene promoter polymorphisms as well as in normolipidemic men and other patient populations (13, 
$18,19)$. However, other studies have concluded that decreased HL activity does not influence susceptibility to CAD (8). Finally, increased HL activity has been reported in patients with $\mathrm{CAD}(20,21)$, and recent analysis of patients participating in the Familial Atherosclerosis Treatment Study demonstrated that the HL promoter gene C514T polymorphism, associated with higher HL activity, more dense LDL, and decreased $\mathrm{HDL}_{2}$ cholesterol (6), predicts favorable changes in coronary artery stenosis with lipid-lowering treatment (21). These combined studies provide evidence supporting both a proatherogenic and antiatherogenic role of HL in humans.

Analyses of transgenic (Tg) and $\mathrm{KO}$ animal models have also provided conflicting data regarding the role that HL plays in atherosclerosis. HL overexpression appears to beneficially alter the plasma lipid profile in mice and rabbits by reducing the amount of cholesterol present in apoB-containing lipoproteins $(16,22)$. In addition, overexpression of human HL reduced the aortic cholesterol content in cholesterol-fed $\mathrm{Tg}$ mice (23). However, despite increases in the cholesterol content of the proatherogenic apoB-containing lipoproteins, HL deficiency significantly lowered aortic atherosclerosis in apoE-KO mice (24). Bergeron et al. (25) have proposed that the reduced aortic atherosclerosis in apoE-KO $\times \mathrm{HL}-\mathrm{KO}$ mice may be due to several factors that include the accumulation of vesicular lipoproteins, which may not be atherogenic and may facilitate reverse cholesterol transport and the accumulation of sphingomyelin-poor $\beta$-VLDL with reduced atherogenic potential. However, there is no evidence to indicate that these vesicular lipoproteins are antiatherogenic. Therefore, accumulation of these particles cannot explain the marked reduction in aortic atherosclerosis observed in this mouse model.

In the present study, we demonstrate that HL deficiency reduces aortic lesion formation not only in apoE$\mathrm{KO}$ mice, as previously reported (24), but also in an independent animal model, the lecithin cholesterol acyltransferase- $\mathrm{Tg}$ (LCAT-Tg) mouse. We use bone marrow transplantation (BMT) to investigate mechanisms, distinct from HL-mediated changes in plasma lipoprotein metabolism, by which HL may modulate atherogenic risk in apoE-KO and LCAT-Tg mice. We provide evidence of HL expression in macrophages present in aortic lesions and demonstrate that despite lack of changes in plasma HL activity or the plasma lipid profile, alterations in macrophage HL expression markedly modify aortic lesion formation in apoE-KO and LCAT-Tg mice. These findings indicate that localized production of $\mathrm{HL}$ by macrophages in the arterial wall may contribute to lesion development by altering macrophage-derived foam cell formation and identify a novel mechanism by which HL modulates atherogenic risk in vivo.

\section{Methods}

Animals. HL-KO (26), apoE-KO (27), and LCAT-Tg $(28,29)$ mice with C57BL/6J backgrounds were cross- bred to generate apoE-KO or LCAT-Tg mice homozygous for HL deficiency. Animals were fed either a rodent autoclaved chow diet containing $4.5 \%$ fat (NIH-07 chow diet; Zeigler Brothers Inc., Gardners, Pennsylvania, USA), a Western diet containing $0.15 \%$ cholesterol and $21 \%$ fat (TD 88137; Harlan Teklad, Madison, Wisconsin, USA), or a cocoa butter diet containing $1.25 \%$ cholesterol and $0.5 \%$ cholic acid (TD 88051, Harlan Teklad). Studies were performed according to a research protocol approved by the Animal Care and Use Committee of the National Heart, Lung, and Blood Institute of the NIH.

Northern blot and in situ RNA bybridization studies. Total RNA and mRNA were isolated from unstimulated peritoneal macrophages obtained from age- and sexmatched mice as described (30). Total RNA $(20 \mu \mathrm{g})$ or mRNA $(2 \mu \mathrm{g})$ was subjected to Northern analysis with either a digoxigenin-labeled HL riboprobe (30) or a ${ }^{32}$ P-labeled 513-bp DraII lipoprotein lipase (LPL) cDNA fragment. The blot was rehybridized with a ${ }^{32}$ P-labeled 693-bp cyclophilin cDNA probe (Ambion, Austin, Texas, USA). HL and LPL mRNA signals were quantified using a scanning densitometer (Molecular Dynamics, Sunnyvale, California, USA) and normalized to cyclophilin mRNA signals. For in situ RNA hybridization, mouse peritoneal macrophages cultured on chamber slides for 5 days were fixed with $4 \%$ formaldehyde. Paraffin-embedded sections of mouse aorta were mounted on poly-L-lysine-coated RNasefree slides and deparaffinized. The macrophages and aortic sections were treated with proteinase $\mathrm{K}(10$ $\mu \mathrm{g} / \mathrm{ml}, 15$ minutes at $37^{\circ} \mathrm{C}$ ) and hybridized overnight at $65^{\circ} \mathrm{C}$ in a humidified chamber containing $5 \mathrm{ng} / \mu \mathrm{l}$ of sense or antisense HL digoxigenin-labeled riboprobes encoding exons 1 and 2 of the HL gene. After hybridization, sections were incubated with alkaline phosphatase-conjugated antidigoxigenin antibody (Roche, Indianapolis, Indiana, USA) and detected with fast red (Roche) according to the manufacturer's instructions. Riboprobe specificity was confirmed by Northern blot analysis of liver RNA from apoE-KO and apoE-KO $\times$ HL-KO mice. Partial purification of HL from peritoneal macrophages by heparin sepharose affinity chromatography and detection of HL by Western blotting were performed as described (30).

Fetal liver cell isolation and sex identification. On day 14 of gestation, pregnant female HL-KO and apoE-KO $\times$ HL-KO mice or LCAT-Tg and LCAT-Tg $\times$ HL-KO mice were sacrificed, the embryos were dissected free from the placenta, and DNA was isolated from the tails of fetuses as described (31). Gender genotyping was performed by PCR to detect the Zfy gene (31). A single-cell suspension of donor fetal liver cells (FLCs) was prepared and cryopreserved as previously reported (31). FLC transplantation. FLCs were used as hematopoietic cells for bone marrow transplantation. Six-week-old female apoE-KO or LCAT-Tg and apoE-KO $\times$ HL-KO or LCAT-Tg $\times$ HL-KO recipient mice were fed acidified water ( $\mathrm{pH} 4.5$ ) containing $100 \mathrm{mg} / \mathrm{l}$ neomycin 
(Sigma-Aldrich, St. Louis, Missouri, USA) and 10 $\mathrm{mg} / \mathrm{l}$ polymyxin B sulfate (Sigma-Aldrich) from 2 weeks before to 2 weeks after BMT. FLC donor cells $\left(5 \times 10^{6}\right.$ in $300 \mu$ l of RPMI-1640 media) were injected into the tail vein of irradiated recipients ( 9 Gy of total-body irradiation). Recipient mice were separated into four separate transplant groups that included (a) apoE-KO mice that received donor FLCs derived from either apoE-KO $\times \mathrm{HL}-\mathrm{KO}$ mice (experimental group) or apoE-KO mice (control group) and (b) apoE$\mathrm{KO} \times \mathrm{HL}-\mathrm{KO}$ mice that received donor FLCs from either apoE-KO mice (experimental group) or apoE$\mathrm{KO} \times \mathrm{HL}-\mathrm{KO}$ mice (control group). After BMT, mice were maintained for 8 weeks on a regular chow diet. In a separate study, apoE-KO and apoE-KO $\times$ HL-KO mice were maintained on a regular chow diet for 1 month after BMT and then fed a Western diet for 6 weeks. The BMT procedure for LCAT-Tg and LCAT-Tg $\times$ HL-KO mice was similar, except that 1 month after BMT mice were fed a cocoa butter diet for 12 weeks.

Genotyping. DNA was prepared from white blood cells and peritoneal macrophages isolated before and 8 weeks after BMT from donor and recipient mice. DNA was PCR amplified using an HL exon 3 forward primer ( $5^{\prime}$-TGGATCTGGAAGATAGTGAGTGCGCTGAA-3') and an HL exon 4 reverse primer $\left(5^{\prime}\right.$-CTGTGATTCTTCCAATCTTGTTCTTCCCG- $3^{\prime}$ ), resulting in the formation of a 1.6-kb fragment in apoE-KO and LCAT-Tg mice and a $2.7-\mathrm{kb}$ fragment in apoE-KO $\times \mathrm{HL}-\mathrm{KO}$ and LCAT-Tg $\times$ HL-KO mice.

$H L$ and LPL activities. Postheparin plasma was obtained 5 minutes after heparin infusion $(500 \mathrm{U} / \mathrm{kg})$ into the mouse tail vein. HL and LPL activities were assayed by incubation with a radiolabeled triolein substrate in the presence or absence of $1 \mathrm{M} \mathrm{NaCl}$ as described (32). To determine the lipase activity in macrophage medium, peritoneal macrophages were cultured in DMEM plus $10 \%$ FBS for 24 hours. The medium was replaced with fresh DMEM without FBS containing $10 \mathrm{U} / \mathrm{ml}$ heparin. After 2 hours, the medium was harvested and the lipase activity was assayed in triplicate as described above. Lipase activity was normalized to protein concentration in the cell homogenate.

Analyses of plasma lipids, lipoproteins, and apolipoproteins. Plasma lipids were determined after a 4-hour fast using enzymatic kits as described $(14,15)$. HDL cholesterol was determined as the cholesterol remaining in the plasma after precipitation of apoB-containing lipoproteins with dextran sulfate (Ciba-Corning, Oberlin, Ohio, USA). Plasma levels of murine apoA-I, apoA-II, and apoB were quantified by sandwich ELISA using polyclonal antibodies against synthetic peptides of mouse apoA-I, apoA-II, and apoB (33). VLDL/IDL, LDL, and HDL lipid content (percentages of cholesterol, phospholipids, and triglycerides) was determined after isolation of HDL by ultracentrifugation and measurement of lipids by enzymatic kits $(14,15)$.

Fast protein liquid chromatography. Plasma lipoproteins from $50 \mu \mathrm{l}$ of pooled mouse plasma $(n=5)$ were sepa- rated by gel filtration using two Superose 6 HR 10/30 columns (Pharmacia Biotech Inc., Piscataway, New Jersey, USA) connected in series $(14,15)$. Lipids in the recovered fractions were assayed as described above. The elution volumes of the plasma lipoproteins separated by fast protein liquid chromatography (FPLC) were $15.0-16.0 \mathrm{ml}$ for VLDL, $20.0-24.0 \mathrm{ml}$ for IDL/LDL, and 30.0-31.0 $\mathrm{ml}$ for HDL.

Uptake of oxidized LDL by macrophages. LDL was isolated from plasma of healthy volunteers by density ultracentrifugation $(1.019<d<1.063)$ and dialyzed against PBS containing $0.01 \%$ EDTA followed by filter sterilization with a $0.2-\mu \mathrm{m}$ filter (Nalgene, Rochester, New York, USA). Oxidized LDL (OxLDL) labeled with tritiated cholesteryl ether $(\mathrm{CEt})\left(\left[{ }^{3} \mathrm{H}\right] \mathrm{CEt}-\right.$ OxLDL) was prepared by overnight incubation of OxLDL with cholesteryl hexadecyl ether [cholesteryl $\left.1,2-{ }^{3} \mathrm{H}(\mathrm{N})\right](40-60 \mathrm{Ci} / \mathrm{mmol}$; New England Nuclear, Boston, Massachusetts, USA), and [ $\left.{ }^{125} \mathrm{I}\right] \mathrm{apoB}-\mathrm{OxLDL}$ was prepared by the iodine monochloride method as described (15). Unstimulated mouse peritoneal macrophages were harvested with DMEM medium and plated in 24-well clustered plates at a density of $5 \times 10^{6}$ cells per well. Nonadherent cells were removed after 3 hours, and the macrophages were incubated with DMEM medium containing 10\% lipoproteindeficient serum (LPDS), penicillin G, streptomycin, and either $50 \mu \mathrm{g} / \mathrm{ml}\left[{ }^{3} \mathrm{H}\right] \mathrm{CEt}-\mathrm{OxLDL}$ or $50 \mu \mathrm{g} / \mathrm{ml}$ [ $\left.{ }^{125} \mathrm{I}\right] \mathrm{apoB}-\mathrm{OxLDL}$ for 24 hours. To determine uptake of $\left[{ }^{3} \mathrm{H}\right] \mathrm{CEt}$, cells were washed with PBS and solubilized in a buffer containing $0.1 \mathrm{M} \mathrm{NaOH}$ and $0.1 \%$ SDS, and aliquots were removed for radioactive counting as well as for protein determination by the bicinchonic acid method (Pierce Chemical, Rockford, Illinois, USA). Degradation of [ $\left.{ }^{125} \mathrm{I}\right] \mathrm{apoB}-\mathrm{OxLDL}$ was determined by measuring trichloroacetic acid (TCA) -soluble ${ }^{125}$ I radioactivity in the medium after precipitation with TCA (final concentration, 10\%). To demonstrate release of macrophage HL into media by heparin, unstimulated peritoneal macrophages were isolated from apoE-KO or apoE-KO $\times$ HL-KO mice and plated as above. After 4 hours of incubation at $37^{\circ} \mathrm{C}$, the medium was replaced by DMEM plus $5 \%$ FCS containing $10 \mathrm{U} / \mathrm{ml}$ heparin (Sigma-Aldrich), and incubation was continued overnight. The next day, $200 \mu$ l of medium was collected, dialyzed against binding buffer, and subjected to heparin sepharose affinity chromatography followed by Western analysis as described (30).

Analysis of aortic lesions. The heart and attached section of ascending aorta were prepared and analyzed as described (34). Macrophages in aortic lesions were identified by immunohistochemistry using a rat monoclonal anti-mouse $\mathrm{Mac}-3$ antigen (Pharmingen, San Diego, California, USA). The tissue sections were deparaffinized, blocked against nonspecific binding with rabbit serum for $45 \mathrm{~min}$ utes, and incubated overnight with the Mac- 3 antibody $(10 \mu \mathrm{g} / \mathrm{ml})$. The sections were then incubated 


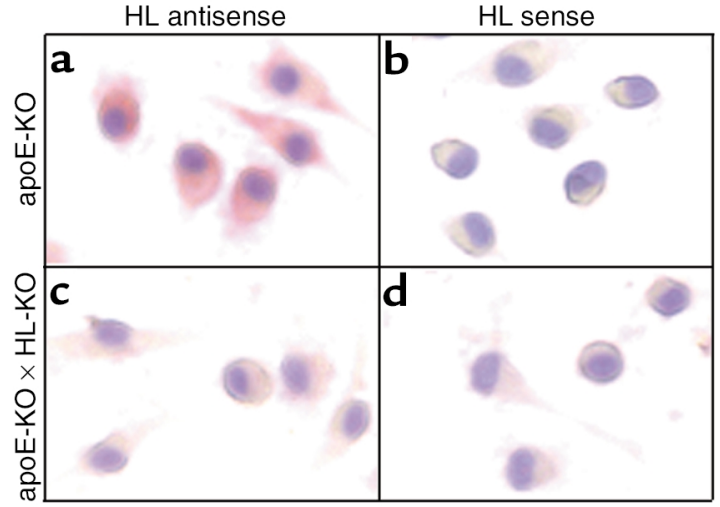

Figure 1

In situ hybridization of HL mRNA in peritoneal macrophages from apoE-KO and apoE-KO $\times$ HL-KO mice. HL mRNA was detected by a mouse $H L$ digoxigenin-labeled antisense riboprobe, visualized by fast red dye in peritoneal macrophages isolated from apoE-KO mice (a). Only background staining was evident in macrophages from apoE-KO $\times$ HL-KO mice (c). Hybridization of peritoneal macrophages from apoE-KO and apoE-KO $\times \mathrm{HL}-\mathrm{KO}$ mice with the $\mathrm{HL}$ sense (control) riboprobe is shown in (b) and (d), respectively.

with a biotinylated rabbit anti-rat IgG antibody and detected with the Tyramide Signal Amplification biotin system (PerkinElmer Life Sciences, Boston, Massachusetts, USA). Bound antibody was visualized with diaminobenzidine. Expression of HL in sections of aortic lesions was determined by in situ RNA hybridization, as described above. The aortas of three mice per group (approximately 10-15 sections per aorta) were examined.

Statistical analysis. Data are presented as means \pm SEM. An unpaired Student's t test was performed for analysis of the plasma lipid concentrations and lipase activities. Nonparametric data were analyzed by the MannWhitney test (Instat Software, Graphpad Inc., San Diego, California, USA).

\section{Results}

$H L$ is expressed in mouse peritoneal macrophages from apoE$K O$ mice. We have previously reported that HL mRNA and protein are present in mouse and human primary and cultured macrophages (30). In situ RNA hybridization analysis using an HL antisense riboprobe demonstrates expression of HL mRNA in peritoneal macrophages isolated from apoE-KO mice (Figure 1a). Only background staining was observed in peritoneal macrophages from apoE-KO $\times \mathrm{HL}-\mathrm{KO}$ mice hybridized with an antisense HL riboprobe (Figure 1c) and in peritoneal macrophages isolated from apoE-KO (Figure $1 \mathrm{~b}$ ) or apoE-KO $\times$ HL-KO (Figure 1d) mice hybridized with the sense HL riboprobe as control. Northern analysis also demonstrated expression of HL by peritoneal macrophages of apoE-KO but not apoE-KO $\times$ HL-KO mice (data not shown). In addition, a $64-\mathrm{kDa}$ HL protein band was detected by Western blot analysis of the $0.8 \mathrm{M} \mathrm{NaCl}$ heparin sepharose elution fraction of apoE-KO but not apoE$\mathrm{KO} \times \mathrm{HL}-\mathrm{KO}$ mouse liver and peritoneal macrophage cell homogenates using anti-mouse HL antibodies (data not shown). These findings demonstrate that $\mathrm{HL}$ is produced by macrophages in apoE-KO mice.

Bone marrow transplantation studies. To evaluate whether expression of HL by macrophages contributed to aortic lesion formation in either apoE-KO or apoE-KO $\times$ HL-KO mice, we performed BMT. This approach has proven very useful in determining the contribution of macrophage gene expression to atherogenesis in vivo $(31,35,36)$. FLCs from both donor apoE-KO and apoE-KO $\times$ HL-KO mice were infused into irradiated apoE-KO and apoE-KO $\times \mathrm{HL}$ $\mathrm{KO}$ recipients. Peripheral blood cell counts returned to normal values in all study groups 4 weeks after transplantation. Successful engraftment of FLCs was determined by PCR using DNA isolated from all four mouse groups before and after transplantation and primers that span exon 3 to exon 4 of the HL gene.
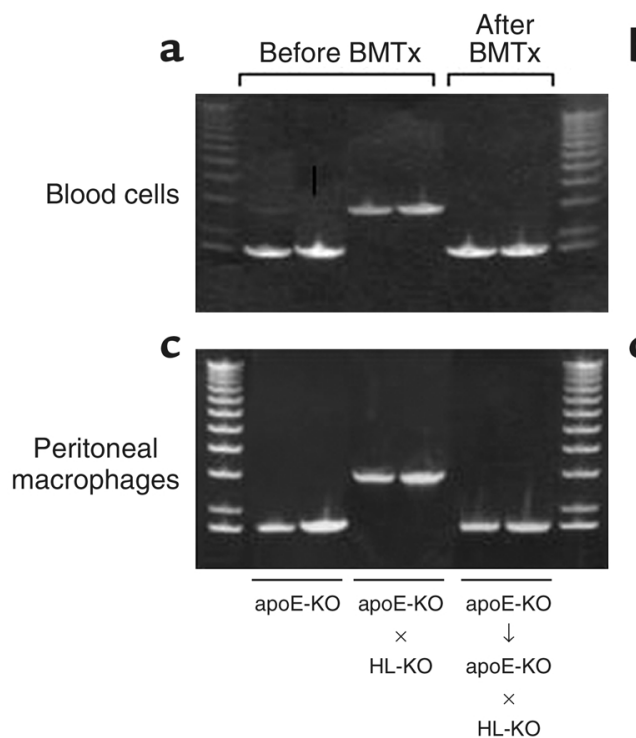

HL-KO
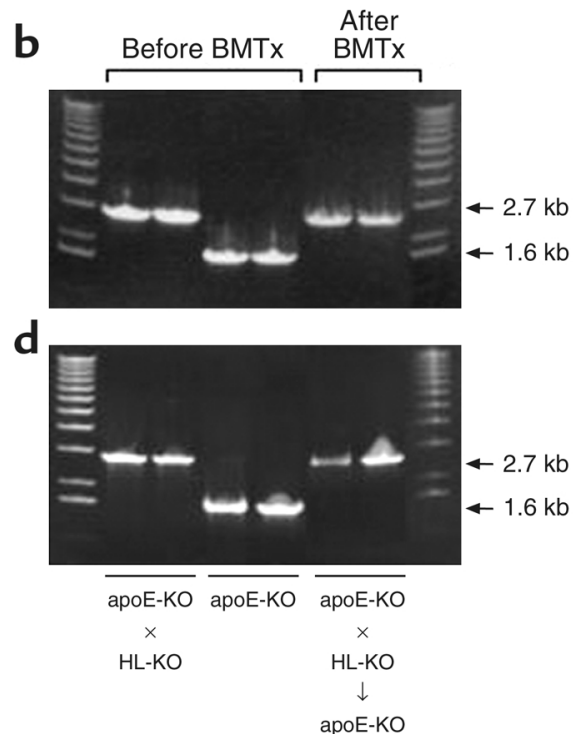

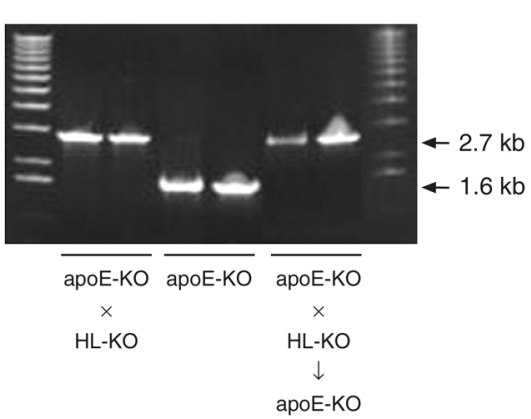

Figure 2

Engraftment of FLCs determined by PCR analysis. DNA isolated from peripheral blood cells and peritoneal macrophages before and after BMT was PCR amplified with primers spanning exons 3 and 4 of the mouse $\mathrm{HL}$ gene. The size of the amplification product of recipient apoE-KO $\times$ HL-KO mice before transplantation $(2.7 \mathrm{~kb})$ changed to that of apoE-KO donor mice $(1.6 \mathrm{~kb})$ after transplantation (a and $\mathbf{c}$ ). Conversely, the size of the amplification product of recipient apoE-KO mice before transplantation $(1.6 \mathrm{~kb})$ changed to that of apoE-KO $\times$ HL-KO donor mice (2.7 $\mathrm{kb}$ ) after transplantation (b and $\mathbf{d})$. 


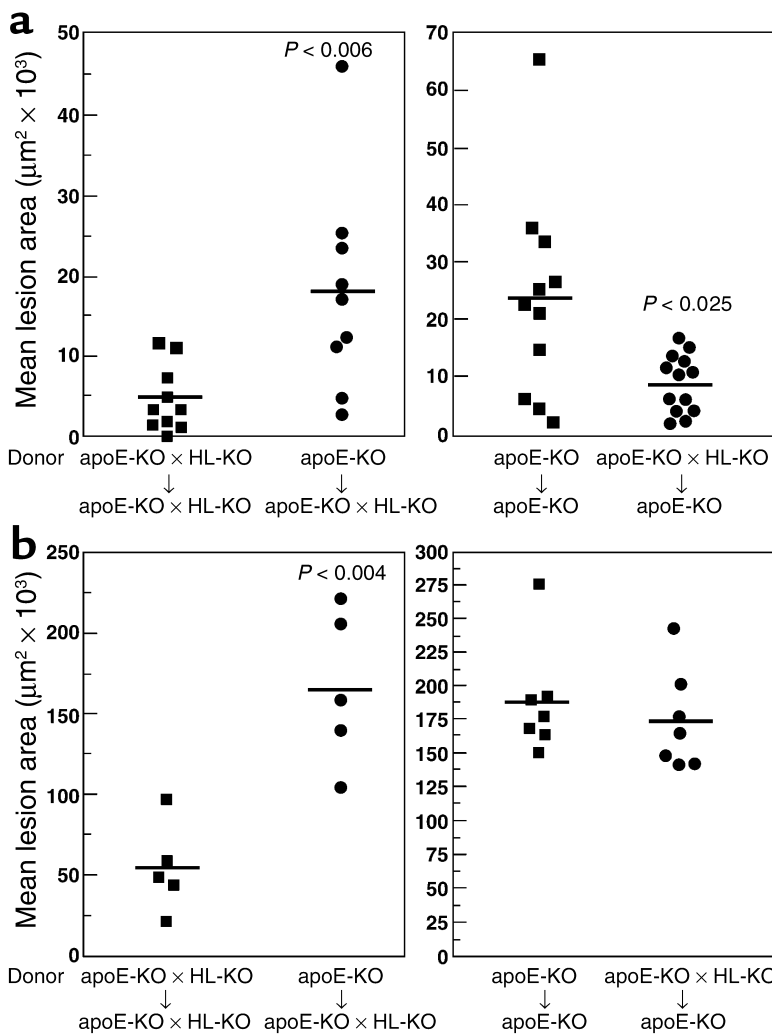

Amplification of DNA isolated from apoE-KO and apoE-KO $\times$ HL-KO mice should lead to the formation of either a $1.6-\mathrm{kb}$ or a $2.7-\mathrm{kb}$ product, respectively (Figure 2). At the time of sacrifice, a single PCR product was amplified from peripheral blood cell and peritoneal macrophage DNA of recipient mice (Figure 2, a-d). Thus, the HL genotype of peripheral blood monocytes as well as peritoneal macrophages isolated from recipient mice had been completely changed to that of donor cells, indicating complete replacement of recipient monocytes/macrophages in these organs. PCR amplification of DNA isolated from the liver of experimental apoE-KO and apoE-KO $\times$ HL-KO recipient mice led to the formation of both $1.6-\mathrm{kb}$ and $2.7-$ $\mathrm{kb}$ products, identifying recipient and donor macrophages in this tissue (data not shown). These findings are consistent with previous studies that report $80-95 \%$ replacement of plasma leukocytes $4-5$ weeks after BMT and 5-20\% replacement of macrophages in the liver 8 weeks after $\operatorname{BMT}(37,38)$ and demonstrate the presence of donor macrophages in blood monocytes, peritoneal macrophages, and liver isolated from recipient mice.

Effect of macrophage HL expression on aortic lesion formation. Analysis of aortic lesion formation in the two experimental and two control study groups was performed after BMT as described (34). To control for the effects of irradiation, which can differentially alter the size and composition of aortic lesions in different regions of the aorta (39), the control study groups

\section{Figure 3}

Analyses of aortic atherosclerosis in recipient mice after BMT on either a regular chow (a) or Western diet (b). On the regular chow diet (a), the mean lesion area was significantly increased in apoE$\mathrm{KO} \times \mathrm{HL}-\mathrm{KO}$ mice transplanted with apoE-KO bone marrow (a, left) (apoE-KO $\rightarrow$ apoE-KO $\times \mathrm{HL}-\mathrm{KO}$, circles) as compared with the control study group (squares). In contrast, the mean lesion area was significantly reduced in apoE-KO mice transplanted with apoE-KO $\times \mathrm{HL}-\mathrm{KO}$ bone marrow (a, right) (apoE-KO $\times \mathrm{HL}-\mathrm{KO} \rightarrow$ apoE-KO, circles) as compared with that of the control study group (squares). On the Western diet (b), similar increases in the mean lesion area of apoE-KO $\times \mathrm{HL}-\mathrm{KO}$ mice transplanted with apoE-KO bone marrow (b, left) (apoE-KO $\rightarrow$ apoE-KO $\times$ HL-KO, circles) were evident as compared with the control study group (squares). However, the mean lesion area was similar between apoE-KO mice transplanted with apoE-KO $\times \mathrm{HL}-\mathrm{KO}$ bone marrow (b, right panel) (apoE-KO $\times \mathrm{HL}-\mathrm{KO} \rightarrow$ apoE-KO, circles) and the control study group (squares).

consisted of recipient mice that received FLCs from donor mice with the same genotype. In apoE-KO $\times$ HL-KO and apoE-KO control mice on a regular chow diet for 8 weeks after BMT (Figure 3a), relatively small lesions with mean proximal aortic lesion areas ranging from $5.0 \times 10^{3} \pm 1.5 \times 10^{3} \mu \mathrm{m}^{2}$ (Figure 3a, left) to $23.2 \times 10^{3} \pm 5.5 \times 10^{3} \mu \mathrm{m}^{2}$ (Figure 3a, right) were evident. In apoE-KO $\times$ HL-KO recipients that received FLCs from apoE-KO donors that expressed HL (apoE-KO $\rightarrow$ apoE-KO $\times$ HL-KO), the mean aortic lesion area was significantly increased (3.4-fold, $P<0.006)$ as compared with apoE-KO $\times$ HL-KO recipients that received FLCs from apoE-KO $\times$ HL-KO donors (apoE-KO $\times$ HL-KO $\rightarrow$ apoE-KO $\times \mathrm{HL}-\mathrm{KO}$, control group) (Figure 3a, left). Conversely, the mean aortic lesion area in apoE-KO recipients that received FLCs from apoE-KO $\times$ HL-KO donors $(a p o E-K O \times$ $\mathrm{HL}-\mathrm{KO} \rightarrow$ apoE-KO) was significantly decreased $(-63 \%, P<0.025)$ as compared with apoE-KO recipients that received FLCs from apoE-KO donors (apoE-KO $\rightarrow$ apoE-KO, control group) (Figure 3a, right). These data indicate that macrophage $\mathrm{HL}$ enhances early aortic lesion formation in apoE-KO and apoE-KO $\times$ HL-KO mice.

Of particular interest is the finding that expression of HL by macrophages in recipient apoE-KO $\times$ $\mathrm{HL}-\mathrm{KO}$ (apoE-KO $\rightarrow$ apoE-KO $\times$ HL-KO) mice raised the mean proximal aortic lesions area to levels similar to that of apoE-KO mice (apoE-KO $\rightarrow$ apoE-KO) that expressed HL in macrophages, liver, and other tissues $\left(18.1 \times 10^{3} \pm 4.4 \times 10^{3} \mu \mathrm{m}^{2}\right.$ versus $23.2 \times 10^{3} \pm 5.5 \times 10^{3} \mu \mathrm{m}^{2}$, respectively; $\left.P>0.05\right)$. Conversely, the absence of HL expression by macrophages in recipient apoE-KO mice (apoE-KO $\times \mathrm{HL}-\mathrm{KO} \rightarrow$ apoE-KO) reduced the mean proximal aortic lesion area to values similar to those of apoE$\mathrm{KO} \times \mathrm{HL}-\mathrm{KO}$ mice $(\mathrm{apoE}-\mathrm{KO} \times \mathrm{HL}-\mathrm{KO} \rightarrow$ apoE-KO $\times$ HL-KO) that had no HL expression in any tissues $\left(8.7 \times 10^{3} \pm 1.4 \times 10^{3} \mu \mathrm{m}^{2}\right.$ versus $5.0 \times 10^{3} \pm 1.5 \times 10^{3}$ $\mu \mathrm{m}^{2}$, respectively; $\left.P>0.05\right)$. Thus, a change in the 
expression of HL by macrophages has a major effect on early aortic lesion formation in the apoE-KO mouse model.

To investigate whether altering macrophage HL expression promotes atherosclerosis in mice with more advanced lesions, we analyzed the proximal aortic lesions of a second group of older mice maintained on a chow diet for 1 month after BMT and then fed a Western diet for 6 weeks (Figure $3 b$ ). The mean lesion size achieved on the Western diet (Figure $3 b$ ) was significantly larger (10- to 20-fold) than that achieved on the regular chow diet (Figure 3a). After BMT, apoE$\mathrm{KO} \rightarrow$ apoE-KO $\times$ HL-KO mice on the Western diet had larger proximal aortic lesions (3-fold, $P<0.004$ ) than the apoE-KO $\times$ HL-KO $\rightarrow$ apoE-KO $\times$ HL-KO control mice (Figure 3b, left). Interestingly, however, no significant difference in proximal aortic lesion area was evident in apoE-KO $\times \mathrm{HL}-\mathrm{KO} \rightarrow$ apoE-KO mice $\left(174 \times 10^{3} \pm 17 \times 10^{3} \mu \mathrm{m}^{2}\right)$ as compared with apoE-KO $\rightarrow$ apoE-KO mice $\left(188 \times 10^{3} \pm 18 \times 10^{3} \mu \mathrm{m}^{2}\right)$ (Figure $3 \mathrm{~b}$, right). On the Western diet, apoE-KO $\times$ HL-KO animals developed smaller, less complex lesions (mean lesion area, $55 \times 10^{3} \pm 13 \times 10^{3} \mu \mathrm{m}^{2}$ ) than apoE$\mathrm{KO}$ mice (mean lesion area, $188 \times 10^{3} \pm 18 \times 10^{3} \mu \mathrm{m}^{2}$ ). These results suggest that in apoE-KO mice, HL expression by macrophages has a greater effect on the earlier rather than the more advanced stages of lesion formation. Similar findings have been reported in analogous studies of LPL-KO macrophage transplantation into LDLR-KO mice, in which the effect of macrophage LPL on the extent of atherosclerosis appeared to be lost in complex, macrophage-poor atherosclerotic lesions (31).

Effect of selective HL expression or deficiency in macrophages on the plasma lipid profile. To address the possibility that macrophage HL expression may alter aortic lesion formation by altering the plasma lipid profile, the plasma lipid profile was examined in control and experimen- tal groups before and after BMT. As previously reported (24), the pre-BMT plasma concentrations of total cholesterol, PLs, cholesterol ester, HDL cholesterol, non-HDL cholesterol, apoA-I, and apoB were significantly $(P<0.05$ for all $)$ increased in apoE-KO $\times$ HL-KO mice versus apoE-KO mice (Table 1 ). Compared with these pre-BMT levels, the plasma total cholesterol, TGs, PLs, cholesterol ester, HDL cholesterol, non-HDL cholesterol, apoA-I, and apoB remained unchanged in apoE-KO and apoE-KO $\times$ HL-KO recipients after fetal liver engraftment (Table 1). Similarly, no differences in the plasma lipid profile between control and experimental groups were detected after receiving a Western diet for 6 weeks (data not shown). FPLC analyses confirmed that there were no changes in the plasma lipoproteins of apoE-KO $\times \mathrm{HL}-\mathrm{KO}$ and apoE-KO mice before and after BMT (data not shown). Thus, selective changes in the expression of HL by macrophages did not have a major effect on the plasma lipid profile in apoE-KO and apoE-KO $\times$ HL-KO mice, indicating minimal contribution by macrophage HL to the metabolism of plasma lipoproteins.

A related but alternative possibility is that macrophage HL may alter the lipid content of plasma lipoproteins. Several laboratories have reported that HL-induced changes in the lipid content of plasma lipoproteins can promote cholesterol uptake by cells in culture (40-43), and Bergeron et al. (25) demonstrated significant differences in the lipid content of VLDL/IDL, LDL, and HDL isolated from apoE-KO versus apoE-KO $\times \mathrm{HL}-\mathrm{KO}$ mice. Enhanced cholesterol uptake of these modified plasma lipoproteins into macrophages could then enhance foam cell formation and promote atherosclerosis. To determine whether changes in macrophage HL expression altered the lipid content of plasma lipoproteins, VLDL/IDL, LDL, and HDL from apoE-KO and apoE-KO $\times$ HL-KO mice before and after BMT were analyzed. Consistent with

Table 1

Lipid profile and HL and LPL activities in apoE/HL-deficient mice and apoE-deficient mice before and after BMT

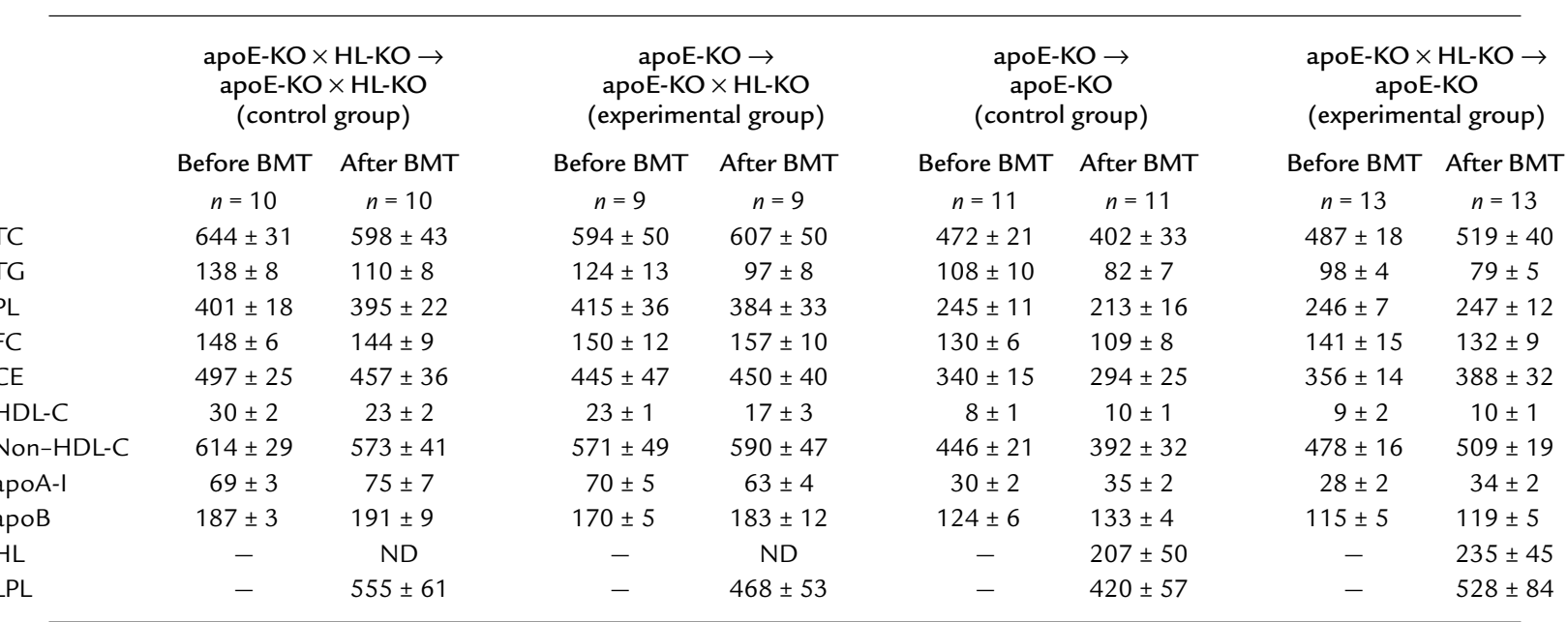

Data are expressed as means \pm SEM. Lipid values are in $\mathrm{mg} / \mathrm{dl}$. HL and LPL activities are expressed in $\mathrm{nmol} / \mathrm{ml} / \mathrm{min}$. There are no significant differences between before and after BMT in each group. TC, total cholesterol; FC, free cholesterol; CE, cholesterol ester; HDL-C, HDL cholesterol; ND, not detectable. 

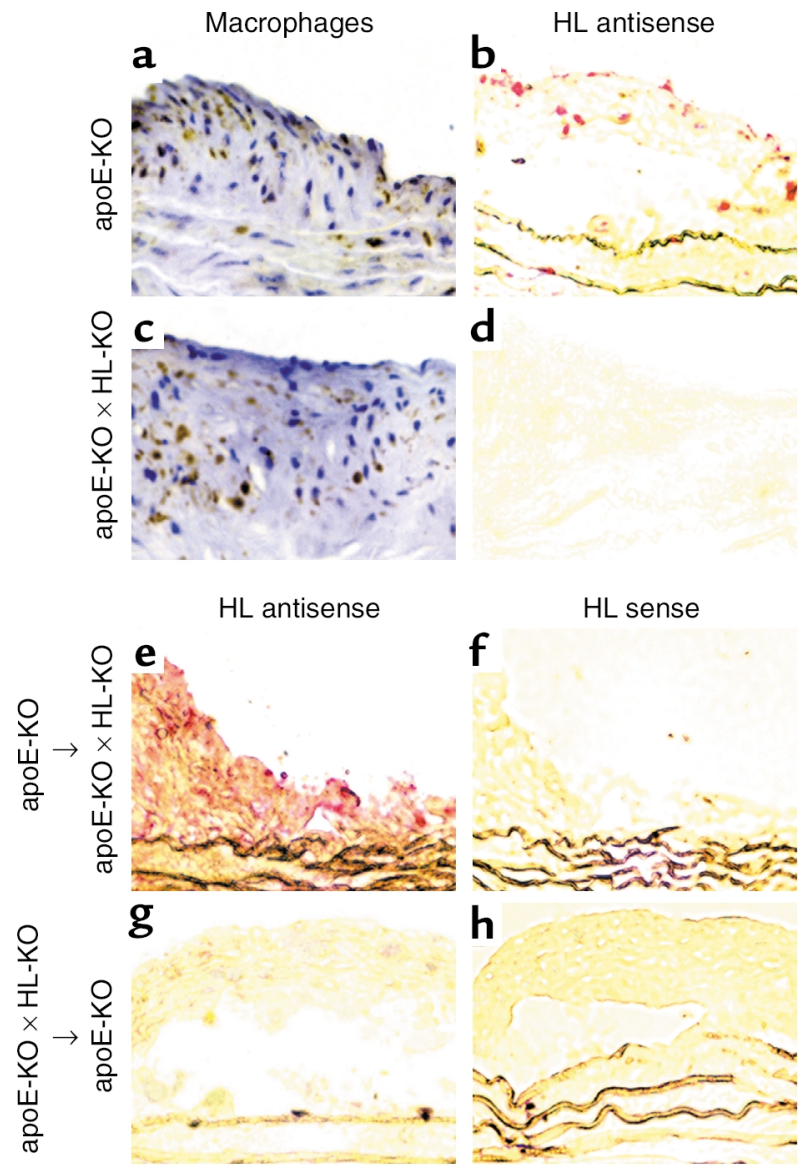

the findings of Bergeron et al. (25), we found baseline differences in the lipid composition of lipoproteins isolated from apoE-KO versus apoE-KO $\times$ HL-KO mice before BMT. However, changes in macrophage HL expression induced by infusion of fetal liver cells from either apoE-KO or apoE-KO $\times$ HL-KO mice did not further alter particle lipid content. Thus, the percent cholesterol, PLs, and TGs in VLDL/IDL (cholesterol, 66-67\%; PLs, 26-27\%; and TGs, 6-7\%), LDL (cholesterol, 64-65\%; PLs, 31.5-32.0\%; and TGs, 3-4\%), and HDL (cholesterol, 45-50\%; PLs, 40-47\%, and TGs, $6-10 \%$ ) isolated from apoE-KO $\rightarrow$ apoE-KO $\times$ HL-KO mice and apoE-KO $\times$ HL-KO $\rightarrow$ apoE-KO $\times$ HL-KO mice after BMT were similar. Likewise, no differences in the lipid content of VLDL/IDL (cholesterol, 70-72\%; PLs, 20-23\%; and TGs, 7-9\%), LDL (cholesterol, 74-76\%; PLs, 21-22\%; and TGs, 3-4\%), and HDL (cholesterol, 54-61\%; PLs, 24-28\%; and TGs, 12-15\%) between apoE-KO $\times$ HL-KO $\rightarrow$ apoE-KO and apoE$\mathrm{KO} \rightarrow$ apoE-KO mice after BMT were noted. These findings suggest minimal contribution by macrophage HL to the hydrolysis of PLs and TGs present in circulating plasma lipoproteins and indicate that changes in aortic lesion formation in recipient mice are not due to alterations in the plasma levels or lipid content of the plasma lipoproteins.

LPL expression in apoE-KO and apoE-KO $\times$ HL-KO mice. Increased postheparin plasma LPL activity has been

\section{Figure 4}

Analysis of $\mathrm{HL}$ expression in aortic lesions after BMT. Macrophages were identified in aortic lesions from apoE-KO (a) and apoE-KO $\times \mathrm{HL}-\mathrm{KO}(\mathbf{c})$ mice by immunohistochemistry using an antibody against the mouse macrophage antigen Mac-3 and counterstained with hematoxylin. HL mRNA was detected by in situ RNA hybridization using the mouse HL digoxigenin-labeled antisense riboprobe ( $\mathbf{b}, \mathbf{d}, \mathbf{e}$, and $\mathbf{g}$ ), which was detected by fast red dye. To enhance visualization of the mRNA, no counterstaining was performed in aortic sections analyzed by in situ RNA hybridization. $\mathrm{HL}$ mRNA is present in aortic lesions from apoE-KO mice (b) but is undetectable in apoE-KO $\times \mathrm{HL}-\mathrm{KO}$ mice $(\mathbf{d})$ before transplantation. After BMT (chow diet), HL mRNA was present in aortic lesions from the apoE-KO $\rightarrow$ apoE-KO $\times \mathrm{HL}-\mathrm{KO}$ mice $(\mathbf{e})$, demonstrating population of aortic lesions in recipient mice by apoE donor macrophages. In contrast, very little HL mRNA was present in aortic lesions from apoE-KO mice after transplantation of donor $\mathrm{HL}-\mathrm{KO} \times$ apoE-KO mouse macrophages (apoE-KO $\times \mathrm{HL}-$ $\mathrm{KO} \rightarrow$ apoE-KO) (g). As expected, after BMT, only background signal was detected in aortic lesions hybridized with the control HL sense riboprobe ( $\mathbf{f}$ and $\mathbf{h})$.

shown to reduce aortic atherosclerosis in transgenic mice (44), whereas increased LPL expression in macrophages promotes lesion formation (31). To evaluate the possibility that changes in HL expression altered LPL expression, we measured the postheparin plasma LPL activity in apoE-KO and apoE-KO $\times$ HL-KO mice after BMT. No significant differences $(P>0.05$ for all) were detected in the postheparin plasma LPL activities present in apoE-KO $\times \mathrm{HL}-\mathrm{KO} \rightarrow$ apoE-KO $\times \mathrm{HL}-\mathrm{KO}$ versus apoE-KO $\rightarrow$ apoE-KO $\times$ HL-KO mice or between apoE$\mathrm{KO} \rightarrow$ apoE-KO and apoE-KO $\times \mathrm{HL}-\mathrm{KO} \rightarrow$ apoE-KO mice (Table 1), although a trend for lower postheparin plasma LPL activities was noted in apoE-KO control mice as compared with apoE-KO $\times$ HL-KO control mice (Table 1) after BMT. We also compared the LPL mRNA levels in pooled peritoneal macrophages isolated from apoE-KO $(n=20)$ and apoE-KO $\times$ HL-KO $(n=20)$ mice by Northern analysis. After normalization to cyclophilin, LPL mRNA levels were $30 \%$ lower in peritoneal macrophages from apoE-KO mice, which express HL, than in peritoneal macrophages from apoE-KO $\times$ HL-KO mice (data not shown). The LPL enzyme activity in cultured peritoneal macrophages was similar between apoE-KO $(n=15,11.6 \pm 1$ $\mathrm{nm} / \mathrm{ml} / \mathrm{min})$ and apoE-KO $\times$ HL-KO $(n=18,13.3 \pm 2$ $\mathrm{nm} / \mathrm{ml} / \mathrm{min}, P>0.05)$ mice. Thus, the proatherogenic effect on aortic lesion formation by macrophage HL expression does not appear to be mediated by increases in LPL transcript or activity levels.

$H L$ is expressed in macrophages present in aortic lesions from apoE-KO $\times H L-K O$ mice after BMT. Local synthesis of $\mathrm{HL}$ in macrophages of aortic lesions could provide an alternative mechanism for the atherogenic effect of macrophage HL. In situ hybridization demonstrates that HL is in fact synthesized by macrophages in aortic lesions (Figure 4). Aortic wall macrophages were identified by immunohistochemistry in apoE-KO (Figure 4a) and apoE-KO $\times \mathrm{HL}-\mathrm{KO}$ (Figure 4c) mice. Before 
transplantation, in situ RNA hybridization using the HL antisense riboprobe demonstrated HL mRNA expression (fast red dye stain) in aortic lesions of apoE$\mathrm{KO}$ mice (Figure $4 \mathrm{~b}$ ) but not apoE-KO $\times \mathrm{HL}-\mathrm{KO}$ mice (Figure 4d). After BMT, in situ RNA hybridization using the HL antisense riboprobe demonstrated that HL mRNA was detected in aortic lesions of apoE-KO $\times$ $\mathrm{HL}-\mathrm{KO}$ mice engrafted with apoE-KO macrophages (Figure 4e). In contrast, most macrophages in aortic lesions of apoE-KO mice transplanted with the apoE$\mathrm{KO} \times \mathrm{HL}-\mathrm{KO}$ bone marrow did not express HL (Figure $4 \mathrm{~g})$. Contiguous sections hybridized with the control HL sense riboprobe showed only background staining (Figure 4, f and h). These data establish localized expression of HL by macrophages in aortic lesions.

Importantly, Figure 4 also indicates that aortic lesions in recipient mice are populated primarily by donor macrophages at the time that aortic lesion formation was determined. Lessner et al. (45) recently demonstrated that after BMT, macrophage-derived foam cells in carotid artery lesions are derived mainly from circulating monocytes rather than from resident macrophages. Nonetheless, the half-life of tissue macrophages, while difficult to estimate, may be in the order of months (46), and it was important to address the

\section{Figure 5}

Plasma lipoprotein profile and aortic atherosclerosis in LCAT-Tg mice before and after BMT. In (a), the plasma lipids of LCAT-Tg mice (black bar) and LCAT-Tg $\times$ HL-KO mice (white bar) are shown. HL deficiency significantly $\left({ }^{*} P<0.05\right)$ raises the plasma concentrations of total cholesterol (TC), PL, cholesterol ester (CE), non-HDL cholesterol (non-HDL-C), and apoB in LCAT-Tg mice. However (b), the mean proximal aortic lesion area of LCAT-Tg $\times$ HL-KO mice ( $n=13$, white bar) after 12 weeks on the cocoa butter diet was significantly reduced $\left({ }^{*} P<0.001\right)$ as compared with LCAT-Tg mice ( $n=11$, black bar). The cholesterol distribution in the plasma lipoproteins of LCAT-Tg $\times \mathrm{HL}-\mathrm{KO}$ mice before (circles) and after (squares) transplantation with LCAT-Tg bone marrow is shown in (c). Similarly, the lipid profile of LCAT-Tg mice before (circles) and after (squares) transplantation with LCAT-Tg $\times$ HL-KO bone marrow is shown in (d). For each study group, $50 \mu \mathrm{l}$ of pooled plasma from five mice $(10 \mu \mathrm{l}$ each) was applied to the FPLC. After $B M T$, the mean lesion area was significantly lowered $\left({ }^{\dagger} P<0.05\right)$ in LCAT-Tg mice transplanted with LCAT-Tg $\times$ HL-KO bone marrow $(\mathbf{e})($ LCAT $\times$ HL-KO $\rightarrow$ LCAT, circles) as compared with the control study group (squares), whereas the mean lesion area of LCAT-Tg $\times$ HL-KO mice transplanted with LCAT-Tg bone marrow $(\mathbf{f})$ (LCAT $\rightarrow$ LCAT $\times$ HL-KO, circles) was significantly increased $(\dagger P<0.05)$ as compared with the control study group (squares). concern that macrophages already present in the vessel wall of recipient mice at the time of BMT could potentially contribute to aortic lesions of our study recipient mice after BMT. The contribution of donor macrophages to aortic lesion development in recipient mice in Figures 3 and 4 was maximized by irradiating recipients at 6 weeks of age, a time when few of the recipient's monocytes/macrophages should have populated the vessel wall (47). Figure 4 demonstrates that at the time of sacrifice, many macrophages present in aortic lesions of recipient mice did in fact exhibit the same HL expression pattern as that of donor and not recipient macrophages, indicating that they were derived from donor bone marrow. The presence of donor macrophages that express HL in aortic lesions of recipient mice and the changes in atherosclerosis after BMT in these mice indicate that HL locally
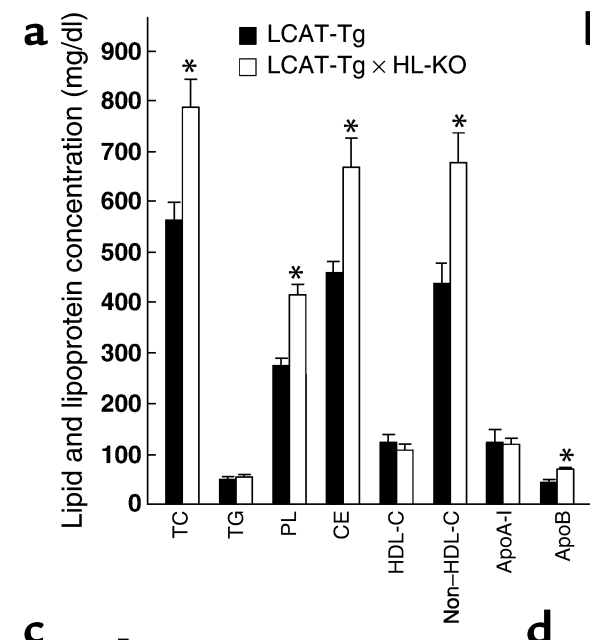

b
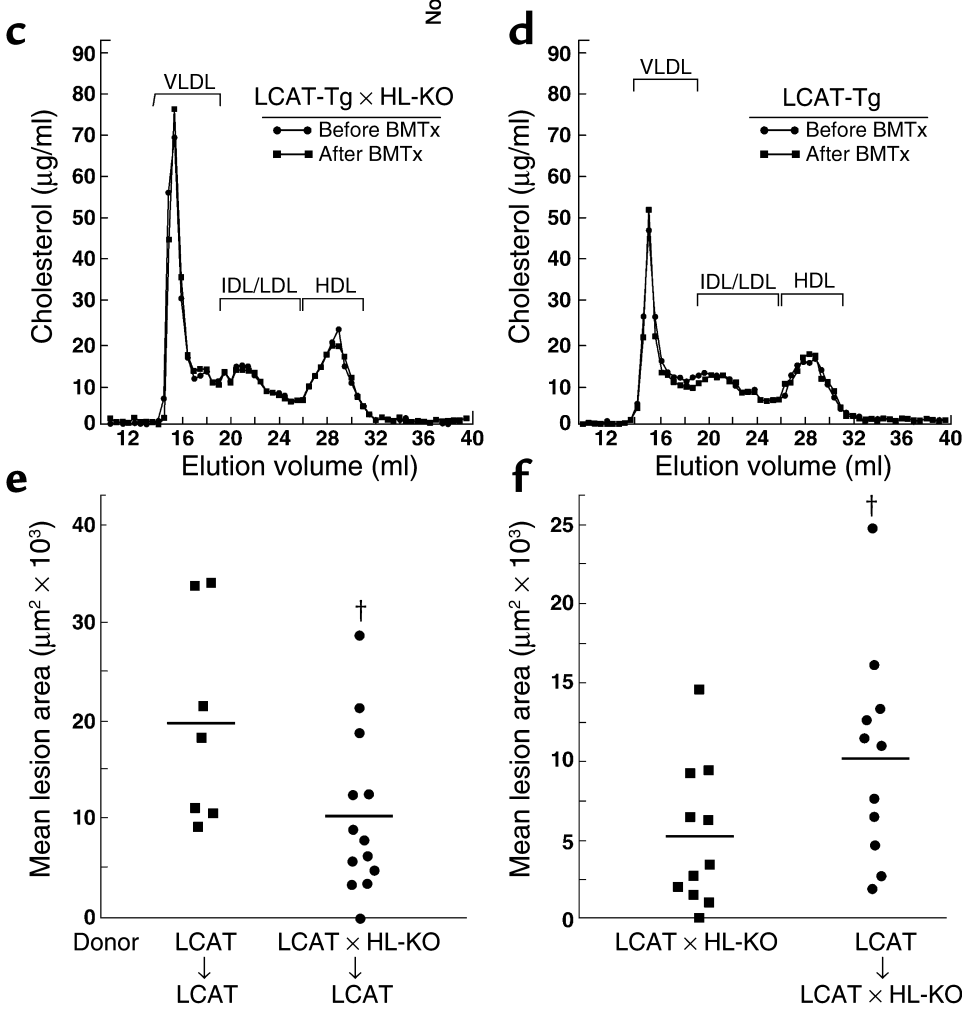
expressed in donor macrophages contributes significantly to aortic lesion formation.

To investigate potential mechanisms by which HL expression by macrophages alters lesion formation, we studied the uptake of OxLDL by peritoneal macrophages isolated from apoE-KO and apoE-KO $\times \mathrm{HL}-\mathrm{KO}$ mice. The uptake of $\left[{ }^{3} \mathrm{H}\right]$ cholesteryl ether from OxLDL and degradation of ${ }^{125}$ I-labeled OxLDL was increased (by 1.25 -fold, $P<0.01$, and 1.3 -fold, $P<0.001$, respectively) in peritoneal macrophages isolated from HLexpressing apoE-KO mice $(610 \pm 40 \mathrm{ng}$ of CEt $/ \mathrm{mg}$ of cell protein and $126 \pm 6 \mathrm{ng}$ of OxLDL/mg of cell protein) as compared with apoE-KO $\times$ HL-KO mice $(470 \pm 20 \mathrm{ng}$ of CEt $/ \mathrm{mg}$ of cell protein and $101 \pm 5 \mathrm{ng}$ of OxLDL/mg of cell protein). These findings are consistent with whole-particle uptake. The presence of HL in both cell homogenates (30) and in the media of cultured peritoneal macrophages isolated from apoE-KO but not apoE-KO $\times \mathrm{HL}-\mathrm{KO}$ mice (data not shown) is consistent with a role of HL in facilitating lipoprotein particle uptake. Aviram et al. (43) have also previously reported that modification of LDL by HL enhances the uptake and accumulation of LDL cholesterol in cultured macrophages. These findings do not rule out the possibility that HL may affect additional cellular processes and functions of macrophages that could enhance lipoprotein particle and lipid uptake.

Our combined studies indicate that HL enhances the uptake and accumulation of cholesterol from LDL and OxLDL by macrophages and identify potential mechanisms by which localized expression of HL in the arterial wall can contribute to lesion formation.

$H L$ deficiency reduces aortic atherosclerosis in LCAT-Tg mice. To investigate whether the effects of macrophage HL expression on atherosclerosis can be extrapolated to other animal models, in particular animal models that express apoE, we performed similar experiments in LCAT-Tg mice backcrossed with HL-KO mice. We have previously reported that overexpression of LCAT in C57BL/ 6 mice significantly enhances aortic atherosclerosis (48). As with apoE-KO mice, HL deficiency also raised the plasma total cholesterol, PL, cholesterol ester, non-HDL cholesterol, and apoB levels (Figure 5a) but significantly lowered diet-induced aortic atherosclerosis (Figure 5b) in LCAT-Tg mice. After $\mathrm{BMT}$ and ingestion of a proatherogenic diet for 12 weeks, no differences in the plasma lipid profile (Figure 5, c and d), plasma apolipoproteins, or postheparin plasma HL and LPL activities (data not shown) between control and experimental groups on the cocoa butter diet were noted. However, aortic atherosclerosis was significantly reduced in LCAT-Tg mice engrafted with HL-deficient macrophages (Figure 5e). Lesion formation was significantly enhanced in LCAT-Tg $\times$ HL-KO mice engrafted with macrophages that expressed HL (Figure 5f). These findings demonstrate that changes in macrophage HL expression can alter aortic lesion formation in a second mouse model that is not deficient in apoE.

\section{Discussion}

Studies in humans and in animal models have provided conflicting data regarding the role that $\mathrm{HL}$ plays in modulating atherogenic risk. Thus, it is unclear whether increased HL expression confers protection from or enhances cardiovascular disease. The findings reported in this manuscript help clarify the role of HL in atherogenesis. The involvement of HL in a novel proatherogenic pathway was first inferred from the unexpected finding that despite increased levels of the proatherogenic apoB-containing lipoproteins, HL deficiency reduces aortic lesion formation in apoE-KO mice (24). In this study, we report that HL deficiency also raises the plasma levels of the apoB-containing plasma lipoproteins but reduces diet-induced atherosclerosis in a different animal model that expresses apoE, the LCAT-Tg mouse. Using BMT, we identify a novel pathway, separable from the function of HL in plasma lipoprotein metabolism, by which the enzyme modulates atherogenic risk in vivo. We demonstrate that HL is produced by macrophages present in aortic lesions, a previously unrecognized site of HL synthesis. Using in situ RNA hybridization, we also establish the presence of donor macrophages in aortic lesions of recipient mice after BMT. Finally, we demonstrate that although liver HL expression remains unaltered, changes in the synthesis of HL by macrophages significantly alters aortic lesion formation. Thus, synthesis of HL in macrophages increased aortic lesion formation by 3.4 -fold in apoE-KO $\times$ HL-KO mice and by 2 -fold in LCAT-Tg $\times$ HL-KO recipient mice, whereas the absence of HL synthesis in macrophages lowered aortic lesion formation by $63 \%$ in apoE-KO and by $57 \%$ in LCAT-Tg recipient mice. These combined data indicate that localized production and accumulation of HL by macrophages present in the vessel wall contributes significantly to aortic lesion formation in two independent atherosusceptible mouse models and identifies an additional mechanism by which HL alters atherosclerosis.

Our results rule out the possibility that HL expression by macrophages creates a proatherogenic plasma lipid profile. Reconstitution of apoE-KO mice with apoE-KO $\times$ HL-KO macrophages did not result in significant changes in the plasma lipid, lipoprotein, and apolipoprotein profiles or postheparin HL activity, despite the inability of donor macrophages to synthesize HL. Similarly, no significant changes were noted in the plasma lipid profile and postheparin HL activity of apoE-KO $\times$ HL-KO mice engrafted with apoE-KO macrophages capable of expressing HL. Moreover, the lipid compositions of VLDL/IDL, $\mathrm{LDL}$, and HDL isolated from the apoE-KO and apoE$\mathrm{KO} \times \mathrm{HL}-\mathrm{KO}$ experimental BMT groups were similar to those of their respective BMT control groups. These findings demonstrate that compared with the liver, the relative contribution of macrophages to the pool of HL present in the circulation or attached to 
the vascular endothelial surface and to the hydrolysis of plasma lipoproteins is not significant. The proatherogenic effect of HL expression in macrophages is therefore not due to alterations in the plasma concentrations or lipid composition of plasma lipoproteins or HL and LPL activity.

Macrophage LPL expression has been shown to enhance aortic lesion formation $(31,49)$. In theory, altering macrophage HL expression could alter macrophage LPL expression, which would then cause the changes in aortic atherosclerosis observed in the BMT studies. However, Northern analysis demonstrated that LPL mRNA levels did not increase in macrophages of apoE-KO mice as compared with apoE-KO $\times$ HL-KO mice. Similarly, macrophage LPL activity did not change, indicating that the proatherogenic effect of HL expression in macrophages is most likely not due to increased LPL expression.

In mice, approximately $50 \%$ of HL circulates in the bloodstream (50). Thus, some of the HL present in aortic lesions could be derived from the liver rather than from lesion macrophages. However, our data indicate that the contribution of the circulating mouse $\mathrm{HL}$ to lesion formation is minimal, since even with a continuous source of HL derived from the apoE-KO recipient liver, the absence of macrophage HL expression after BMT reduced atherogenic risk in apoE-KO mice to levels similar to those of transplanted control apoE-KO $\times$ HL-KO mice. Thus, even if some fraction of $\mathrm{HL}$ in aortic lesions were derived from liver, it is the macrophage-synthesized HL that is primarily responsible for formation of aortic lesions.

Since transplanted macrophages are not restricted to the artery but may repopulate other tissues in the mouse, and since the number of macrophages in the vessel wall is small compared with the total body monocyte and macrophage pool sizes (approximately $10^{7}$ and $10^{8}$, respectively) (51), the potential contribution by macrophages outside aortic lesions to changes in atherosclerosis should be considered. One possible scenario involves the transport of HL produced by external macrophages to the vessel wall, where it would then participate in lesion formation. However, we have shown that the amount of HL produced by macrophages is small (30) compared with the amount of HL produced by the liver. In addition, as noted above, even the large quantities of plasma $\mathrm{HL}$ derived from liver was not sufficient to affect aortic lesion formation, so the smaller quantities of HL derived from external macrophages and circulating monocytes could not have an effect.

$\mathrm{HL}$ is known to facilitate the uptake of lipoproteins by macrophages (43). It is therefore possible that expression of HL by monocytes/macrophages outside of the vessel wall could deplete the plasma pool of modified lipoproteins, sequestering these proatherogenic particles away from lesion macrophages. However, this scenario would lead to reduced atherosclerosis in apoE-KO $\times$ HL-KO mice that express HL only in macrophages (apoE-KO $\rightarrow$ apoE-KO $\times$ HL-KO), rather than the 3.4-fold increase in mean aortic lesion area observed in this study (Figure 3). Conversely, the absence of monocytes/macrophages that can express HL should increase the plasma pool of modified lipoproteins available to lesion macrophages and increase lesion formation in transplanted apoE-KO mice (apoE-KO $\times$ HL-KO $\rightarrow$ apoE-KO), findings opposite to what we actually observe. Consistently, HL expression by macrophages did not alter the plasma lipid profile.

Macrophage HL appears to accelerate lesion development at early rather than late stages of aortic atherosclerosis. HL is clearly not essential for initiation or progression of lesions, as apoE-KO $\times \mathrm{HL}-\mathrm{KO} \rightarrow$ apoE$\mathrm{KO} \times \mathrm{HL}-\mathrm{KO}$ mice, which never express $\mathrm{HL}$ in any tissue, can still develop significant lesions $\left(>50 \times 10^{3} \mu \mathrm{m}^{2}\right.$ on a Western diet) (Figure 3b). Macrophage HL expression does, however, enhance the rate at which small lesions progress to larger lesions. HL expressed only from macrophages can enhance atherosclerosis in mice with lesions ranging from $5 \times 10^{3} \mu \mathrm{m}^{2}$ (Figures $3 \mathrm{a}$, left, and 5f, right) to $50 \times 10^{3} \mu^{2}$ (Figure 3b, left). Consistently, macrophage HL deficiency can retard development of lesions smaller than $10 \times 10^{3} \mu \mathrm{m}^{2}$ (Figures $3 \mathrm{a}$, right, and $5 \mathrm{e}$, left). Thus, macrophage HL is capable of enhancing development of atherosclerotic lesions at early-to-middle stages in lesion development. In contrast, macrophage HL deficiency did not significantly reduce the proximal aortic atherosclerosis in the apoE-KO recipient mice that developed more advanced lesions $\left(188 \times 10^{3} \mu \mathrm{m}^{2}\right)$ on the Western diet (Figure $3 \mathrm{~b}$, right). In this experiment, study mice were maintained on a regular chow diet for one month after BMT and then placed on a Western diet for 6 weeks. Before the shift to the Western diet, the apoE-KO recipient strains must have had relatively small lesions $\left(<25 \times 10^{3} \mu \mathrm{m}^{2}\right.$, which was the lesion size for apoE-KO mice after BMT followed by 12 weeks on a chow diet) (Figure 3a). Before the shift to the Western diet, as in the regular chow BMT study, HL deficiency in apoE$\mathrm{KO}$ recipients (Figure $3 \mathrm{~b}$, right) most likely did initially slow the development of atherosclerosis in the proximal aorta. However, upon addition of the Western diet, lesion progression proceeds rapidly in apoE-KO mice (47), and late-stage processes appeared to overwhelm the contribution of macrophage HL to lesion development (Figure 3b, right). Our data support the hypothesis that $\mathrm{HL}$ is not required for initiation of atherosclerosis but operates to promote formation of atherosclerotic lesions at early-to-middle, but not late, stages of lesion development.

These findings are completely analogous to results obtained by transplanting LPL-KO macrophages into LDLR-KO mice (31), where a decrease in mean lesion area in the proximal aorta was observed in early but not late lesions. Babaev et al. (31) note that since early lesions are characterized by the accumulation of macrophage-derived cells, the presence or absence of 
macrophage LPL (and by analogy, HL) is expected to have a strong influence on lesion formation. The more complex late lesions have a smaller proportion of macrophages and an increased number of smooth muscle cells; consequently, the effects of macrophageproduced LPL or HL might be expected to be reduced. HL and LPL would thus be anticipated to influence formation of atherosclerotic lesions at an early stage in lesion development, when the major site of lipid accumulation is intracellular, in macrophage-derived foam cells (47). In advanced lesions, other processes such as smooth cell proliferation, fibrous plaque formation, and extracellular lipid accumulation (47) are taking place and are likely to overwhelm the importance of the macrophage lipase effect.

Our results support a mechanism in which HL expression in macrophages promotes aortic lesion formation by local production of HL by macrophages in the vessel wall. Localized production of HL by lesion macrophages may result in a paracrine-like effect, leading to significant accumulation and increased effective concentrations of HL within the vessel wall that may have a major effect on lesion development. Consistent with this hypothesis, we demonstrated that expression of HL by macrophages enhances the uptake of OxLDL by these cells in culture. Previous studies have also shown that HL induces lipoprotein uptake and cholesterol accumulation by macrophages (43). Thus, accumulation of HL produced by macrophages present in the vessel wall, a finding established in this study by in situ RNA hybridization, may enhance foam cell formation in vivo.

Further support for this concept can be found in the literature. LPL promotes lipoprotein internalization and lipid accumulation by macrophages through local lipolysis and bridging of lipoproteins (43, 52-54). In addition, localized production of LPL by macrophages within the arterial wall has been shown to promote foam cell and lesion formation (31), enhance monocyte recruitment and retention in the vessel wall $(31,55-57)$, and increase retention of lipoproteins in the extracellular matrix through LPLmediated bridging of lipoproteins (58-60). All of these processes enhance aortic atherosclerosis by promoting foam cell formation.

The strong effect of HL on lesion development, despite its relatively low level of expression in macrophages, raises the interesting possibility that HL may affect additional cellular processes and functions of macrophages that could enhance lesion formation by altering processes such as receptor gene expression, cytokine production, or chemotaxis. These questions will be addressed in future studies.

In summary, the present study demonstrates that (a) macrophages present in the arterial wall express HL (b) expression of HL by monocytes/macrophages does not contribute significantly to changes in the plasma lipid profile or postheparin HL activity, and (c) the production of HL by macrophages promotes foam cell formation and aortic atherosclerosis in two different mouse models, apoE-KO and LCAT-Tg mice. These combined findings indicate that localized expression of HL by macrophages in the vessel wall may significantly enhance early aortic lesion formation and provide evidence to support a novel mechanism, separate from the role of HL in plasma lipoprotein metabolism, by which HL modulates atherogenic risk in vivo.

\section{Acknowledgments}

We thank Cindy McFarland for excellent technical support.

1. Olivecrona, G. and Olivecrona, T. 1995. Triglyceride lipases and atherosclerosis. Curr. Opin. Lipidol. 6:291-305.

2. Doolittle, M.H., Wong, H., Davis, R.C., and Schotz, M.C. 1987. Synthesis of hepatic lipase in liver and extrahepatic tissues. J. Lipid Res. 28:1326-1334.

3. Vieira-van Bruggen, D., et al. 1997. Hepatic lipase gene expression is transiently induced by gonadotropic hormones in rat ovaries. Mol. Cell. Endocrinol. 126:35-40.

4. Brunzell, J.D., and Deeb, S.S. 2001. Familial lipoprotein lipase deficiency, apoC-II deficiency, and hepatic lipase deficiency. In The metabolic and molecular bases of inherited disease. C.R. et al., editors. McGrawHill. New York, New York, USA. 2789-2816.

5. Thuren, T. 2000. Hepatic lipase and HDL metabolism. Curr. Opin. Lipidol. 11:277-283.

6. Zambon, A., Deeb, S.S., Hokanson, J.E., Brown, B.G., and Brunzell, J.D. 1998. Common variants in the promoter of the hepatic lipase gene are associated with lower levels of hepatic lipase activity, buoyant LDL, and higher $\mathrm{HDL}_{2}$ cholesterol. Arterioscler. Thromb. Vasc. Biol. 18:1723-1729.

7. Jansen, H., et al. 1999. The T allele of the hepatic lipase promoter variant $\mathrm{C}-480 \mathrm{~T}$ is associated with increased fasting lipids and HDL and increased preprandial and postprandial LPCIII: B: European Atherosclerosis Research Study (EARS) II. Arterioscler. Thromb. Vasc. Biol. 19:303-308.

8. Shohet, R.V., et al. 1999. Hepatic lipase (LIPC) promoter polymorphism in men with coronary artery disease. Allele frequency and effects on hepatic lipase activity and plasma HDL-C concentrations. Arterioscler. Thromb. Vasc. Biol. 19:1975-1978.

9. Couture, P., et al. 2000. Association of the C-514T polymorphism in the hepatic lipase gene with variations in lipoprotein subclass profiles: the Framingham Offspring Study. Arterioscler. Thromb. Vasc. Biol. 20:815-822.

10. Cohen, J.C., Vega, G.L., and Grundy, S.M. 1999. Hepatic lipase: new insights from genetic and metabolic studies. Curr. Opin. Lipidol. 10:259-267.

11. Campos, H., Dreon, D.M., and Krauss, R.M. 1995. Associations of hepatic and lipoprotein lipase activities with changes in dietary composition and low density lipoprotein subclasses. J. Lipid Res. 36:462-472.

12. Beisiegel, U. 1996. New aspects on the role of plasma lipases in lipoprotein catabolism and atherosclerosis. Atherosclerosis. 124:1-8.

13. Santamarina-Fojo, S., Haudenschild, C., and Amar, M. 1998. The role of hepatic lipase in lipoprotein metabolism and atherosclerosis. Curr. Opin. Lipidol. 9:211-219.

14. Dugi, K.A., et al. 2000. In vivo evidence for both lipolytic and nonlipolytic function of hepatic lipase in the metabolism of high density lipoproteins. Arterioscler. Thromb. Vasc. Biol. 20:793-800.

15. Amar, M.J.A., et al. 1998. Hepatic lipase facilitates the selective uptake of cholesteryl esters from remnant lipoproteins in apoE deficient mice. J. Lipid Res. 39:2436-2442.

16. Dichek, H.L., et al. 2001. Hepatic lipase overexpression lowers remnant and LDL levels by a noncatalytic mechanism in LDL receptor-deficient mice. J. Lipid Res. 42:201-210.

17. Zambon, A., Deeb, S.S., Bensadoun, A., Foster, K.E., and Brunzell, J.D. 2000. In vivo evidence of a role for hepatic lipase in human apoB-containing lipoprotein metabolism, independent of its lipolytic activity. J. Lipid Res. 41:2094-2099.

18. Dugi, K.A, et al. 2001. Low hepatic lipase activity is a novel risk factor for coronary artery disease. Circulation. 104:3057-3062.

19. Hokanson, J.E., et al. 2002. A common promoter polymorphism in the hepatic lipase gene $(L I P C-480 C>T)$ is associated with an increase in coronary calcification in type 1 diabetes. Diabetes. 51:1208-1213.

20. Katzel, L.I., et al. 1992. Reduced $\mathrm{HDL}_{2}$ cholesterol subspecies and elevated postheparin hepatic lipase activity in older men with abdominal 
obesity and asymptomatic myocardial ischemia. Arterioscler. Thromb. 12:814-823.

21. Zambon, A., Deeb, S.S., Brown, B.G., Hokanson, J.E., and Brunzell, J.D 2001. Common hepatic lipase gene promoter variant determines clinical response to intensive lipid-lowering treatment. Circulation. 103:792-798.

22. Fan, J., et al. 1994. Overexpression of hepatic lipase in transgenic rabbits leads to a marked reduction of plasma high density lipoproteins and intermediate density lipoproteins. Proc. Natl. Acad. Sci. U. S. A. 91:8724-8728.

23. Busch, S.J., et al. 1994. Human hepatic triglyceride lipase expression reduces high density lipoprotein and aortic cholesterol in cholesterolfed transgenic mice. J. Biol. Chem. 269:16376-16382.

24. Mezdour, H., Jones, R., Dengremont, C., Castro, G., and Maeda, N. 1997. Hepatic lipase deficiency increases plasma cholesterol but reduces susceptibility to atherosclerosis in apolipoprotein E-deficient mice. J. Biol. Chem. 272:13570-13575.

25. Bergeron, N., et al. 1998. Lamellar lipoproteins uniquely contribute to hyperlipidemia in mice doubly deficient in apolipoprotein $\mathrm{E}$ and hepatic lipase. Proc. Natl. Acad. Sci. U. S. A. 95:15647-15652.

26. Homanics, G.E., et al. 1995. Mild dyslipidemia in mice following targeted inactivation of the hepatic lipase gene. J. Biol. Chem. 270:2974-2980.

27. Zhang, S.H., Reddick, R.L., Piedrahita, J.A., and Maeda, N. 1992. Spontaneous hypercholesterolemia and arterial lesions in mice lacking apolipoprotein E. Science. 258:468-471.

28. Vaisman, B.L., et al. 1995. Overexpression of human lecithin cholesterol acyltransferase leads to hyperalphalipoproteinemia in transgenic mice. J. Biol. Chem. 270:12269-12275.

29. Berard, A.M., et al. 1997. High plasma HDL concentrations associated with enhanced atherosclerosis in transgenic mice overexpressing lecithin cholesteryl acyltransferase. Nat. Med. 3:744-749.

30. Gonzalez-Navarro, H., et al. 2002. Identification of mouse and human macrophages as a site of synthesis of hepatic lipase. J. Lipid Res. 43:671-675.

31. Babaev, V.R., Patel, M.B., Semenkovich, C.F., Fazio, S., and Linton, M.F. 2000. Macrophage lipoprotein lipase promotes foam cell formation and atherosclerosis in low density lipoprotein receptor-deficient mice. J. Biol. Chem. 34:26293-26299.

32. Iverius, P.-H., and Brunzell, J.D. 1985. Human adipose tissue lipoprotein lipase: changes with feeding and relation to postheparin plasma enzyme. Am. J. Physiol. 249:E107-E114.

33. Sullivan, P.M., et al. 1997. Targeted replacement of the mouse apolipoprotein E gene with the common human APOE3 allele enhances diet-induced hypercholesterolemia and atherosclerosis. J. Biol. Chem. 272:17972-17980.

34. Paigen, B., Morrow, A., Holmes, P.A., Mitchell, D., and Williams, R.A. 1987. Quantitative assessment of atherosclerotic lesions in mice. Atherosclerosis. 68:231-240.

35. Linton, M.F., and Fazio, S. 1999. Macrophages, lipoprotein metabolism, and atherosclerosis: insights from murine bone marrow transplantation studies. Curr. Opin. Lipidol. 10:97-105.

36. Curtiss, L.K., and Boisvert, W.A. 2000. Apolipoprotein E and atherosclerosis. Curr. Opin. Lipidol. 11:243-251.

37. Krall, W.J., Challita, P.M., Perlmutter, L.S., Skelton, D.C., and Kohn, D.B. 1994. Cells expressing human glucocerebrosidase from a retroviral vector repopulate macrophages and central nervous system microglia after murine bone marrow transplantation. Blood. 83:2737-2748

38. Kennedy, D.W., and Abkowitz, J.L. 1997. Kinetics of central nervous system microglial and macrophage engraftment: analysis using a transgenic bone marrow transplantation model. Blood. 90:986-993.

39. Schiller, N.K., Kubo, N., Boisvert, W.A., and Curtiss, L.K. 2001. Effect of Y-irradiation and bone marrow transplantation on atherosclerosis in LDL receptor-deficient mice. Arterioscler. Thromb. Vasc. Biol. 21:1674.

40. Bamberger, M., Glick, J.M., and Rothblat, G.H. 1983. Hepatic lipase stimulates the uptake of high density lipoprotein cholesterol by hepatoma cells. J. Lipid Res. 24:869-876.
41. Auwerx, J.H., Marzetta, C.A., Hokanson, J.E., and Brunzell, J.D. 1989. Large buoyant LDL-like particles in hepatic lipase deficiency. Arteriosclerosis. 9:319-325.

42. Choi, S.Y., Komaromy, M.C., Chen, J., Fong, L.G., and Cooper, A.D. 1994. Acceleration of uptake of LDL but not chylomicrons or chylomicron remnants by cells that secrete apoE and hepatic lipase. J. Lipid Res. 35:848-859.

43. Aviram, M., Bierman, E.L., and Chait, A. 1988. Modification of low density lipoprotein by lipoprotein lipase or hepatic lipase induces enhanced uptake and cholesterol accumulation in cells. J. Biol. Chem. 263:15416-15422.

44. Yagyu, H., et al. 1999. Overexpression of lipoprotein lipase protects against atherosclerosis in apolipoprotein E knockout mice. J. Lipid Res. 40:1677-1685.

45. Lessner, S.M., Prado, H.L., Waller, E.K., and Galis, Z.S. 2002. Atherosclerotic lesions grow through recruitment and proliferation of circulating monocytes in a murine model. Am. J. Pathol. 160:2145-2155.

46. van Furth, R. 1970. Origin and kinetics of monocytes and macrophages. Semin. Hematol. 7:125-141.

47. Nakashima, Y., Plump, A.S., Raines, E.W., Breslow, J.L., and Ross, R. 1994. ApoE-deficient mice develop lesions of all phases of atherosclerosis throughout the arterial tree. Arterioscler. Thromb. 14:133-140.

48. Vaisman, B.L., et al. 2001. ABCA1 overexpression leads to hyperalphalipoproteinemia and increased biliary cholesterol excretion in transgenic mice. J. Clin. Invest. 108:303-309. doi:10.1172/JCI200112517.

49. Babaev, V.R., et al. 1999. Macrophage lipoprotein lipase promotes foam cell formation and atherosclerosis in vivo. J. Clin. Invest. 103:1697-1705.

50. Peterson, J., Bengtsson-Olivecrona, G., and Olivecrona, T. 1986. Mouse preheparin plasma contains high levels of hepatic lipase with low affinity for heparin. Biochim. Biophys. Acta. 878:65-70.

51. Lee, S.H., Starkey, P.M., and Gordon, S. 1985. Quantitative analysis of total macrophage content in adult mouse tissues. Immunochemical studies with monoclonal antibody F4/80. J. Exp. Med. 161:475-489.

52. Lindqvist, P., Ostlund-Lindqvist, A.M., Witztum, J.L., Steinberg, D., and Little, J.A. 1983. The role of lipoprotein lipase in the metabolism of triglyceride-rich lipoproteins by macrophages. J. Biol. Chem. 258:9086-9092.

53. Wang, X., Greilberger, J., and Jurgens, G. 2000. Calcium and lipoprotein lipase synergistically enhance the binding and uptake of native and oxidized LDL in mouse peritoneal macrophages. Atherosclerosis. 150:357-363.

54. Rumsey, S.C., Obunike, J.C., Arad, Y., Deckelbaum, R.J., and Goldberg, I.J. 1992. Lipoprotein lipase-mediated uptake and degradation of low density lipoproteins by fibroblasts and macrophages. J. Clin. Invest. 90:1504-1512.

55. Saxena, U., Kulkarni, N.M., Ferguson, E., and Newton, R.S. 1992. Lipoprotein lipase-mediated lipolysis of very low density lipoproteins increases monocyte adhesion to aortic endothelial cells. Biochem. Biophys. Res. Commun. 189:1653-1658.

56. Auerbach, B.J., et al. 1999. Lipoprotein lipase greatly enhances the retention of lipoprotein(a) to endothelial cell-matrix. Atherosclerosis. 142:89-96.

57. Tabas, I., et al. 1993. Lipoprotein lipase and sphingomyelinase synergistically enhance the association of atherogenic lipoproteins with smooth muscle cells and extracellular matrix. A possible mechanism for low density lipoprotein and lipoprotein(a) retention and macrophage foam cell formation. J. Biol. Chem. 268:20419-20432.

58. Saxena, U., Klein, M.G., Vanni, T.M., and Goldberg, I.J. 1992. Lipoprotein lipase increases low density lipoprotein retention by subendothelial cell matrix. J. Clin. Invest. 89:373-380.

59. Auerbach, B.J., Bisgaier, C.L., Wolle, J., and Saxena, U. 1996. Oxidation of low density lipoproteins greatly enhances their association with lipoprotein lipase anchored to endothelial cell matrix. J. Biol. Chem. 271:1329-1335.

60. Saxena, U., Ferguson, E., Auerbach, B.J., and Bisgaier, C.L. 1993. Lipoprotein lipase facilitates very low density lipoprotein binding to the subendothelial cell matrix. Biochem. Biophys. Res. Comm. 194:769-774. 